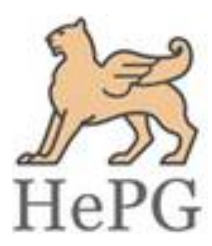

ISSN: 2348-1900

Plant Science Today

http://www.plantsciencetoday.online

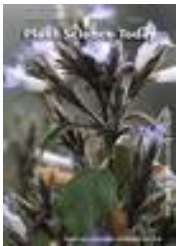

OPEN $\odot$ ACCESS

Research Article

\title{
Physiological responses of sub1A QTL under induced dehydration stress for varying days in rice
}

\author{
Indraneel Saha, Bipul Sarkar, Arijit Ghosh, Arnab Kumar De \& Malay Kumar Adak* \\ Plant Physiology and Plant Molecular Biology Research Unit, Department of Botany, University of Kalyani, Kalyani 741 235, West Bengal., India
}

\section{Article history}

Received: 09 November 2019

Accepted: 06 January 2019

Published: 06 February 2020

\section{Publisher}

Horizon e-Publishing Group

\author{
*Correspondence \\ Malay Kumar Adak \\ 凶mkadak09@gmail.com
}

\begin{abstract}
This study analysed the rice genotype with sub1A quantitative trait loci that may interact with ongoing exposure of dehydration. cv. Swarna Sub1 had more nutrients efficiency with increased membrane permeability than cv. Swarna. sub1A QTL with its expression to water / osmotic deficit, however, indirectly to impede the oxidative stress under dehydration might help cv. Swarna Sub1. At maximum dehydration cv. Swarna Sub1 had 1.12 fold excess electrolyte leakages than cv. Swarna under dehydration. cv. Swarna Sub1 had better Nicotinamide adenine dinucleotide phosphate-malic enzyme activity to secure carbon dioxide exchange. A proportional increase in enzyme activity all through dehydration stress maximize under light in cv. Swarna Sub1. At maximum dehydration cv. Swarna Sub1 at saturating substrate concentration was increased by 1.12 fold than other cultivar. The ratio of glutathione (GSH:GSSG) more depleted in cv. Swarna Sub1 through the dehydration period. cv. Swarna could be more promising to retrieve the activity by 1.80 fold than cv. Swarna Sub1 under maximum dehydration. Dehydroascorbate reductase activity was also maintained in cv. Swarna with 1.20 fold ahead than cv. Swarna Sub1 under same condition. As a biomarker of oxidative stress cv. Swarna Sub1 appeared to be less sensitive with the loss of protein oxidation, however, recorded with $25 \%$ less carbonyl content than cv. Swarna. Both the genotypes had scored a significant sensitivity with tissue specific distribution for reactive oxygen species as detected by histochemical assay.
\end{abstract}

Keywords: rice; sub1A QTL; physiological activity; reactive oxygen species; dehydration stress

Abbreviations: NADP-ME, Nicotinamide adenine dinucleotide phosphate-malic enzyme; GSH, Glutathione; GSSG, Glutathione disulfide; ROS, Reactive oxygen species; RBD, Randomised block design; $\mathbf{N a H C O}_{3}$, Sodium bicarbonate; EDTA, Ethylenediaminetetraacetic acid; PMSF, Phenylmethylsulfonyl fluoride; DTT, Dithiothreitol; BSA, Bovine serum albumin; NEM, NEthylmaleimide; DHAR, Dehydroascorbate reductase; DNPH, 2, 4-Dinitrophenylhydrazine; $\mathbf{H}_{2} \mathbf{O}_{2}$, Hydrogen peroxide; DAB, 3'3'-diaminobenzidine; NBT, Nitroblue tetrazolium; NADP, Nicotinamide adenine dinucleotide phosphate; NADP(H), Nicotinamide adenine dinucleotide phosphate hydrogen.

Citation: Saha I, Sarkar B, Ghosh A, De A K, Adak M K. Physiological responses of sub1A QTL under induced dehydration stress for varying days in rice. Plant Science Today 2020;7(1):112121. https://doi.org/10.14719/pst.2020.7.1.654

Copyright: (c) Saha et. al. (2020). This is an open-access article distributed under the terms of the Creative Commons Attribution License, which permits unrestricted use, distribution, and reproduction in any medium, provided the original author and source are credited (https://creativecommons.org/licenses/by/4.0/).

Indexing: Plant Science Today is covered by Scopus, WoS, BIOSIS Previews, ESCI, CAS, AGRIS, UGC-CARE, CABI, Google Scholar, etc. Full list at http://www.plantsciencetoday.online

\section{Introduction}

In rice abundance or excess water creates the problem for a transient anaerobic stress. In rice cultivation the stagnation of water within a certain date also creates some sort of oxygen deficiency (1). Still, a prolonged duration of such condition with 
superseded water level around the height of the plants creates the submergence stress. This hypoxic or anoxic condition becomes more vulnerable for the plants at post submergence period. On recedes of water level after a long submergence certainly exposes of the leafy shoot to high oxygen tension (2). The turnover of anoxic to oxygenic condition is an outcome of some reactive oxygen species (ROS). The development of ROS is most favoured particularly, with high irradiance is also happened in post submergence condition. Therefore, change over anoxic to oxygenic condition and perception of high irradiance causes a misbalance of cellular redox. In rice genotype post submergence oxidative stress mediated reactions are highly variable. Tall/semitall indica genotypes are equally sensitive to lodging under submergence and post submergence oxidative stress (3). The dwarf cultivated genotypes are moderately sensitive, still, vary according to agronomic condition. A depletion of soil nitrogen and water deficit may also be inductive for more proneness to oxidative stress after submergence. A fall in grain yield is quite significant throughout the submerged prone area in rice cultivation with reference to Southeast Asia (4). Reduction in plant growth and dry matter, photosynthetic gas exchange, energy yielding metabolisms under anoxic/hypoxic condition are the most common physiological constraints in rice (5). The most studied rice genotype to interact with submergence is with the genetic elements as sub1A. It is a quantitative trait locus (QTL) that employs ethylene induced physiological reactions to facilitate suppressed growth and anaerobic respiration. cv. Swarna Sub1 such a genotype having the variability with sub1A QTL could exercise the quiescence strategy (6). The functionales of this QTL otherwise facilitates the regulation of reserved carbohydrates mobilization through inhibition of gibberellic acid synthesis and activities. However, during post submergence the development of redox and its interaction with ethylene is still yet to be ascertained. So, changes of oxidative stress with functioning of sub1A QTL in cv. Swarna Sub1 would be interesting to document. It would also be imperative to look into the behaviour of ethylene $\left(\mathrm{C}_{2} \mathrm{H}_{4}\right)$ responsiveness through sub1A QTL under water deficit condition. This is compatible to the occurrence of tissue dehydration as occurs at post submergence. In fact, rice seedlings may also be water deficit due to poor root hydraulic conductivity even under complete submergence. Therefore, post submergence would be compatible to some sort of dehydration stress in rice fallows, particularly, with water availability below the field capacity (7). With this fact the present study would be relevant to monitor the reactions of sub1A QTL when exposed to withdrawn irrigation. With this background we have designed a study with one sub1A QTL possessing genotype cv. Swarna Sub1 in comparison with non sub1A QTL (cv. Swarna) with analysis of dehydration and oxidative stress modules.

\section{Materials and methods}

\section{Development of rice seedlings, Drought stress and sample collection:}

The present experiment was carried out in the experimental garden and laboratory of Plant Physiology in the Department of Botany, University of Kalyani, Kalyani $\left(22^{\circ} 58^{\prime} 30^{\prime \prime N}\right.$, $\left.88^{\circ} 26^{\prime} 04^{\prime} \mathrm{E}\right)$, West Bengal, India. Certified seeds of cv. Swarna (submergence intolerant line) and cv. Swarna Sub1 (submergence tolerant line) were collected from Chinsurah Rice Research Station, West Bengal, India. After sterilization, seeds were transferred for germination for $4-5$ days at $30^{\circ} \mathrm{C} \pm$ $2^{\circ} \mathrm{C}$ available in incubator. 7 days old seedlings (10 hills per pot) were grown compacted with alluvial soil containing sand, slit and clay ( $\mathrm{pH}$ 6.8) for one week under 16 light: 8 dark cycles. The irradiance was maintained with $900-1200 \mu \mathrm{Em}^{-2} \mathrm{~s}^{-1}, 85 \%$ of relative humidity, $30^{\circ} \mathrm{C} \pm 2^{\circ} \mathrm{C}$ of temperature. Under such condition plants were kept undisturbed for acclimatization for 7 days. 7 days old plants were induced to dehydration in each pot by withholding the irrigation for consecutive 2, 4 and 8 days duration. Sampling of the intact seedlings at intervals of those 2,4 and 8 days were done since the plants failed to survive within 10 days. A control set was made where no withdrawn of irrigation was done. The plants were replicated thrice in randomised block design (RBD) in independent experiment. Biochemical analysis as different parameters from plant samples were done at each interval of 2,4 and 8 days as described following.

\section{Assay of electrolyte leakage:}

Intact seedlings were harvested from each treatment. The membrane permeability or electrolyte leakage was done from the roots of plants under each treatment. Initially, roots were thoroughly washed with de-ionised water, incubated over night at $37^{\circ} \mathrm{C}$ on shaker. Conductivity of the solution was read. Thereafter, the roots in the solution were autoclaved at $120^{\circ} \mathrm{C}$ for $15 \mathrm{~min}$. On cooling at $37^{\circ} \mathrm{C}$, final conductivity of the same solution was measured by a conductivity meter (Dm 50) (8). From the ratio of initial to final conductivity the electrolyte leakage was determined.

\section{Assay of NADP-malic enzyme:}

Leaves from seedlings were kept in dark for 4 hours following incubation in $2.0 \mathrm{mM} \mathrm{NaHCO}_{3}$ induction buffer solution for 2 hours in the form of leaf disks. The sets were illuminated with the light intensity around 1000-1200 $\mu \mathrm{Em}^{-2} \mathrm{~s}^{-1}$. After illumination the leaf disks were extracted in a buffer: $100 \mathrm{mM}$ Tris-hydrochloride (pH 7), $15 \mathrm{mM}$ $\mathrm{MgCl}_{2}$ (magnesium chloride), $2 \mathrm{mM} \mathrm{KH} \mathrm{PO}_{4}-\mathrm{K}_{2} \mathrm{HPO}_{4}$ 
(monopotassium phosphate-dipotassium phosphate), $0.1 \mathrm{mM}$ EDTA, $0.1 \mathrm{mM}$ PMSF, $0.1 \mathrm{mM}$ mercaptoethanol and $10 \%$ glycerol or sucrose. The supernatant on centrifugation at $12,000 \mathrm{Xg}$ for 15 min at $4^{\circ} \mathrm{C}$ was partially purified with $80 \%$ ammonium sulphate cut. The purified fraction of protein was taken for enzyme assay in ice-cold condition. The assay of enzyme was carried out at $37^{\circ} \mathrm{C}$ in a reaction buffer of $2.5 \mathrm{ml}$ with $100 \mathrm{mM}$ Tris-hydrochloride ( $\mathrm{pH}$ 8), $10 \mathrm{mM} \mathrm{MgCl}_{2}, 0.1 \mathrm{mM}$ DTT, $0.5 \mathrm{mM}$ nicotinamide adenine dinucleotide phosphate (NADP) and $100 \mu \mathrm{g}$ equivalent protein leaves extract. Malate with varying concentrations $(0.01 \mu \mathrm{mol}$ as limiting and $4.0 \mu \mathrm{mol}$ as saturated) were considered. The enzyme activity (EC: 1.1.1.40) was determined by read the reduction of NADP at $340 \mathrm{~nm}$ (9). BSA was used as standard to quantify the protein with Bradford reagent.

\section{Assay of GSH and GSSG:}

Plant samples (1.0 g) from respective treatments were homogenised in TCA (trichloroacetic acid) solution under cold condition and centrifuged at $15,000 \mathrm{Xg}$ for $10 \mathrm{~min}$ at $4^{\circ} \mathrm{C}$. For the assay of GSH (EC: 1.8.1.7) the supernatant was taken in $0.1 \mathrm{mM}$ phosphate buffer (pH 8.0). An aliquot of supernatant with the assay mixture containing phosphate buffer and $0.1 \%(\mathrm{w} / \mathrm{v}) o$-phthalaldehyde was incubated at room temperature (excitation) and $350 \mathrm{~nm}$ (emission). For the assay of GSSG (EC: 1.8.1.7) the supernatant was incubated with $0.4 \mathrm{M}$ NEM for half an hour. Then, the mixture was diluted by adding $0.1 \mathrm{~N} \mathrm{NaOH}$ and $\mathrm{pH}$ was adjusted to 12.0. Thereafter, an aliquot of the mixture was added to the same buffer as taken for GSH except $0.1 \mathrm{~N} \mathrm{NaOH}$ for reading the fluorescence intensity at $420 \mathrm{~nm}$ (excitation) and $350 \mathrm{~nm}$ (emission). With the help of standard glutathione the content of GSH and GSSG were calculated (10).

\section{Assay of DHAR activity:}

Plant samples (1.0 g) from each treatment were used and crushed in liquid nitrogen. Then, the samples were homogenized in $50 \mathrm{mM}$ potassiumphosphate buffer (pH 7.0) and centrifuged at $12,000 \mathrm{Xg}$ for $15 \mathrm{~min}$ at $4^{\circ} \mathrm{C}$. Thereafter, the enzyme extract was added to the reaction mixture containing $50 \mathrm{mM}$ potassium-phosphate buffer $(\mathrm{pH}$ 7.0), $2.5 \mathrm{mM} \mathrm{GSH}$ and $0.1 \mathrm{mM}$ dihydroxyacetone. The DHAR activity (EC: 1.8.5.1) was calculated from the change in absorbance at $265 \mathrm{~nm}$ for 1 min with the help of extinction coefficient of 14/mM/cm (11).

\section{Assay of protein oxidation:}

Plant samples $(1.0 \mathrm{~g})$ were crushed in $6 \%$ SDS (sodium dodecyl sulfate) and incubated $\left(37^{\circ} \mathrm{C}, 30\right.$ min). To this $10 \mathrm{mM}$ DNPH in $1.5 \mathrm{ml}$ TCA was added following centrifugation at 15,000 $\mathrm{Xg}$ and protein pellet was recovered which was completely suspended in $0.2 \mathrm{M}$ sodium-phosphate buffer ( $\mathrm{pH}$ 7.0). The absorbance was read at 360 nm (12). Finally the protein-carbonyl complex content was calculated with the help of molar extinction coefficient $\left(530 \mathrm{M}^{-1} \mathrm{~cm}^{-1}\right)$ of DNPH.

\section{Histochemical detection of hydrogen peroxide $\left(\mathrm{H}_{2} \mathrm{O}_{2}\right)$ :}

Leaves and roots were cut into uniform sizes followed by washing thoroughly with double distilled water. Accumulation of $\mathrm{H}_{2} \mathrm{O}_{2}$ was detected with in-vivo infiltration by DAB (13). Samples were infiltrated with freshly prepared $5 \mathrm{mM}$ DAB solution in phosphate buffer for over-night in dark. Then $\mathrm{pH}$ of the buffer was adjusted to $\mathrm{pH}$ 3.8. Next, the leaves made de-chlorophyllous with lactic acid-glycerol-ethanol solution (1:1:4-v/v/v) following boiling in for $10 \mathrm{~min}$. The distributions of hydrogen peroxide were captured by digital camera (Dewinter).

\section{Histochemical detection of superoxide $\left(\mathrm{O}_{2}{ }^{-}\right)$:}

Leaves and roots were incubated with $50 \mathrm{mM}$ phosphate buffer containing $6 \mathrm{mM}$ NBT salt $(\mathrm{pH}$ 4.8) for overnight. Thereafter, the leaves were made de-chlorophyllous using lactic acid-glycerolethanol solution (1:1:4-v/v/v) following boiling in water-bath for $10 \mathrm{~min}$ (14). Then the dark blue patches of formazan compound were captured by digital camera (Dewinter).

\section{Statistical analysis:}

For the statistical analysis the data of the present experiment were subjected to analysis of variance coupled with student's t-test (SPSS software IBMversion 26, USA) and the significance of variance was tested at $\mathrm{p} \leq 0.05, \mathrm{p} \leq 0.01$ and $\mathrm{p} \leq 0.001$ levels.

\section{Results}

The present work is embodied with some cellular responses to dehydration inundation of sub1A QTL for two rice cultivars: cv. Swarna and Swarna Sub1. Initially, as perception of water deficit, the membrane responded well through loss of osmolytes for both the genotypes (Fig. 1).

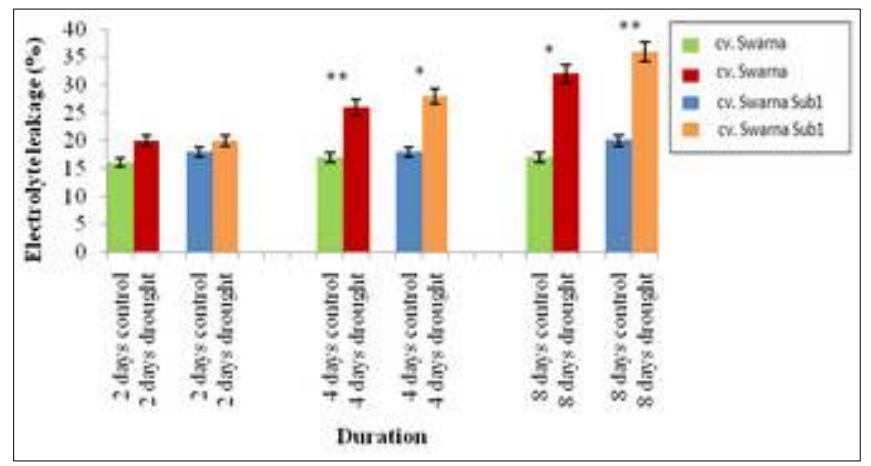

Fig. 1. Changes of electrolyte leakage through days of dehydration of cv. Swarna and Swarna Sub1. Data are presented in bars with \pm SE $(n=3)$ from independent experimental sets and the significant values were represented as $^{*}(\mathrm{p} \leq 0.05),{ }^{* *}(\mathrm{p} \leq 0.01)$ and ${ }^{* * *}(\mathrm{p} \leq 0.001)$ by student's t-test to denote the significant differences between control and treatment through duration of dehydration. 
The electrolyte leakage could be granted as reliable index to over loss the ions all through the days, however, maximum was recorded at 8 days. Thus, the ranges of electrolyte loss under treatments were in the order of 20 to $32 \%$ for cv. Swarna and 20 to $36 \%$ for cv. Swarna Sub1. This is significant both at $p \leq 0.05$ and $p \leq 0.01$ levels which also predict that cv. Swarna under stress condition could minimize the electrolyte loss because, under dehydration it recorded $1.17 \%$ less electrolyte leakage than the other variety. In the intermediate period cv. Swarna Sub1 was also prone to dehydration with significant electrolyte loss. This predicts ion conductivity would be more affected for cv. Swarna Sub1 to perceive the dehydration induced membrane damages. As already described that rice is a $\mathrm{C}_{3}$ species and not exercised the $\mathrm{CO}_{2}$ concentration mechanism with existing de-carboxylation regulation.

sub1A QTL while analysis with respect to $\mathrm{C}_{3}$, however, non photosynthetic specific NADP-ME activities showed a significant ( $\mathrm{p} \leq 0.05,0.01$ and 0.001) variations through the substrate concentrations (Fig. 2). With concentration variability of substrate by 0.01 and $4.0 \mu \mathrm{mol}$, NADP-ME activity was approaching in a consistent manner regardless of the rice genotypes. This is also compatible even with days of dehydration stress. Thus, in light (at $0.01 \mu \mathrm{mol}$ concentration) the ranges of enzyme activity under control were in the ranges of 0.08 to 0.1 and 0.09 to 0.12 $\mu \mathrm{mol} / \mathrm{min} / \mathrm{g}$ for cv. Swarna and Swarna Sub1 respectively (Fig. 2a). With the increasing days of dehydration stress at $4.0 \mu \mathrm{mol}$ concentration in light the activity changes in a similar manner with up regulation through ranges of 0.12 to 0.15 and 0.13 to $0.14 \mu \mathrm{mol} / \mathrm{min} / \mathrm{g}$ respectively for those two varieties under control (Fig. 2c). The induction of the enzyme for both cv. Swarna and Swarna Sub1 recorded a linear increase in a day dependent manner for the treatments. At 8 days maximum changes in activities were 2.20 and 2.33 fold respectively for those two varieties under light at $0.01 \mu \mathrm{mol}$ concentration. Under same concentration when plants were incubated in dark the changes of activities at maximum days of dehydration were 3.0 and 1.7 fold for cv. Swarna and Swarna Sub1 respectively (Fig. 2b) cv. Swarna Sub1 had recorded the higher activity by 1.05 fold than cv. Swarna at highest concentration and duration at malate and days respectively (Fig. 2d).

With the induction of dehydration to sub1A QTL, it is quite obvious to have a change of redox leading to oxidative stress. In our earlier experiment the sensitivity of sub1A QTL to prolong submergence and its recovery have documented a fair amount of ROS generation. Contextually, the homeostasis of redox system and its recovery is monitored through cellular context of glutathione (Fig. 3a). Initially, the glutathione with its two forms reduced (GSH) and oxidised (GSSG) were linearly increased through the duration of 2, 4 and 8 days, however, under control. Still, dehydration treatment had significantly $(\mathrm{p} \leq 0.01$ and 0.001 ) consumed the GSH almost in a compatible manner of both the varieties. As compared to control, the maximum subdued effect of GSH content was recorded 46.13 and $43.42 \%$ at 8 days for cv.

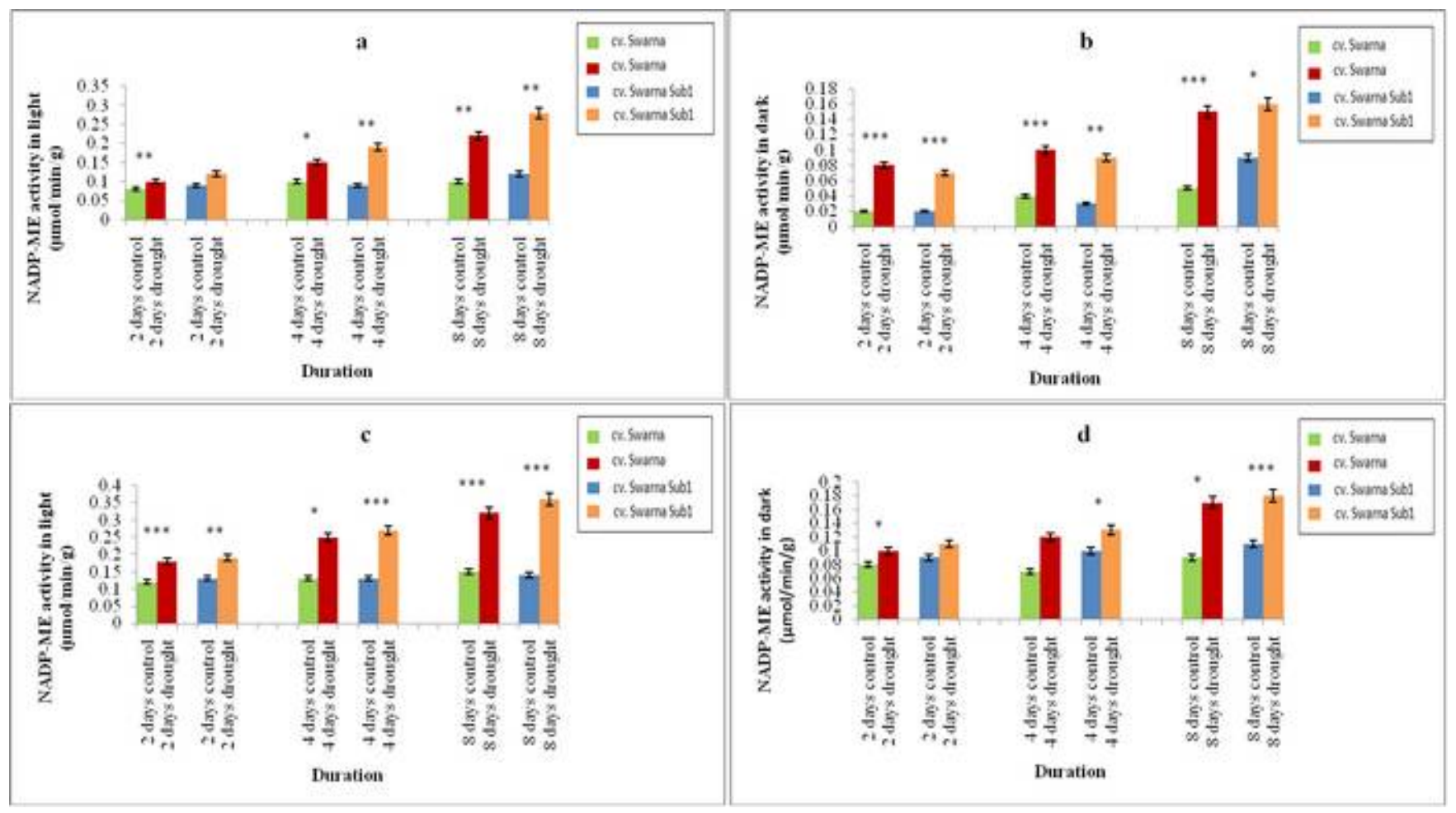

Fig. 2. Changes of NADP-ME activity at $0.01 \mu \mathrm{mol}$ concentration in light (a), dark (b) and at $4.0 \mu \mathrm{mol}$ concentration in light (c), dark (d) through days of dehydration of cv. Swarna and Swarna Sub1. Data are presented in bars with \pm SE ( $\mathrm{n}=3$ ) from independent experimental sets and the significant values were represented as * $(p \leq 0.05)$, ** $(p \leq 0.01)$ and $* * *(p \leq 0.001)$ by student's t-test to denote the significant differences between control and treatment through duration of dehydration. 


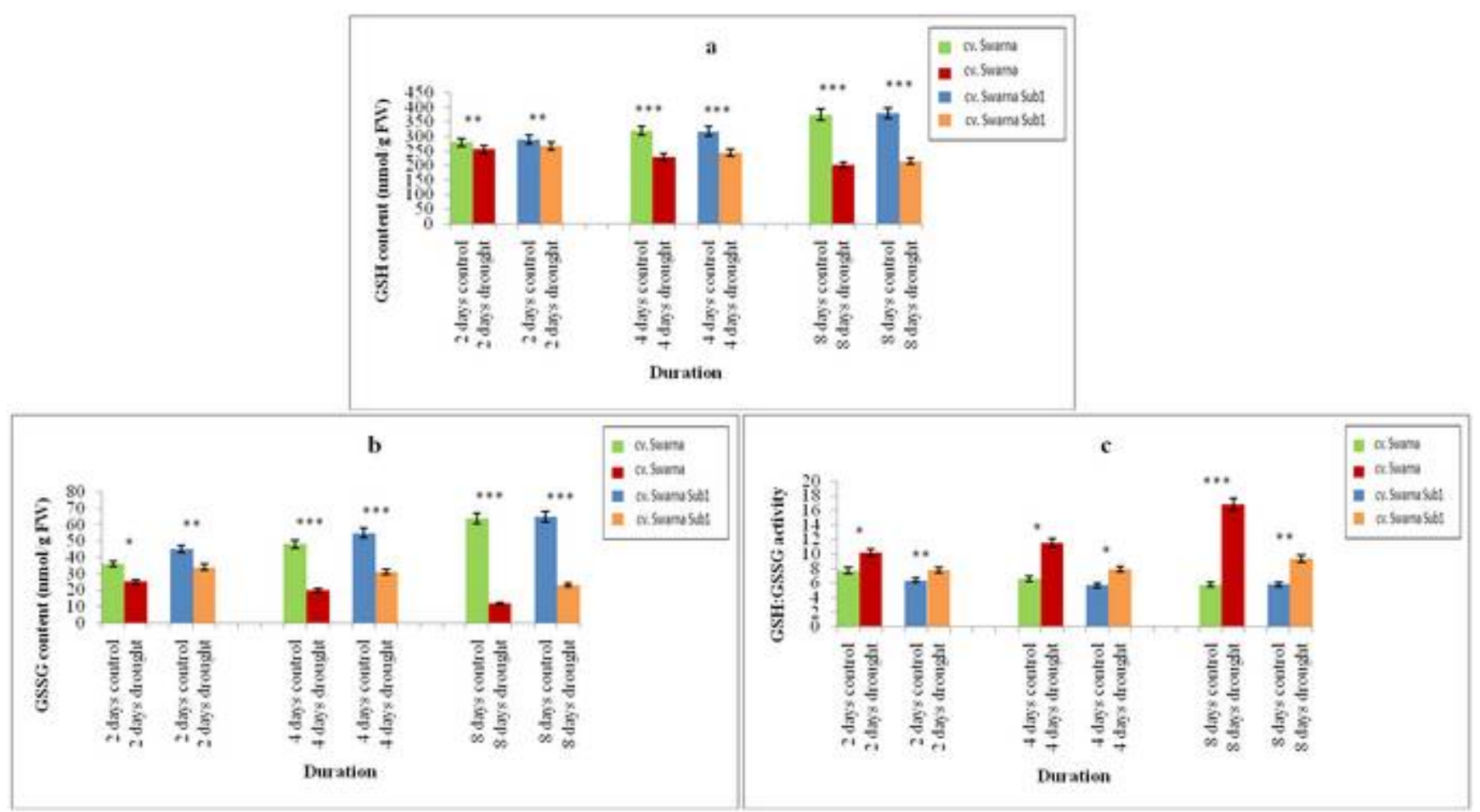

Fig. 3. Changes of GSH content (a), GSSG content (b) and GSH:GSSG activity (c) through days of dehydration of cv. Swarna and Swarna Sub1. Data are presented in bars with \pm SE $(n=3)$ from independent experimental sets and the significant values were represented as ${ }^{*}(p \leq 0.05),{ }^{* *}(p \leq 0.01)$ and ${ }^{* * *}(p \leq 0.001)$ by student's t-test to denote the significant differences between control and treatment through duration of dehydration

Swarna and Swarna Sub1 respectively. On the other hand the oxidised form of glutathione (GSSG) was also up regulated through the dehydration days (Fig. 3b). Thus, the GSSG content for cv. Swarna and Swarna Sub1 remained always up regulated through the ranges of 25 to 12 and 34 to $23 \mathrm{nmol} / \mathrm{g}$ respectively all through the treatments. The increase in activity under dehydration cv. Swarna Sub1 always had been ahead of cv. Swarna for GSSG. Ratio of GSH and GSSG is also played a more reliable index to assay the oxidative stress tolerance in crops and that also is established in the present experiment (Fig. 3c). GSH:GSSG had always been higher in cv. Swarna than Swarna Sub1 at 2 and 4 days. It showed an increase of 1.20 and 1.15 fold at respective days for

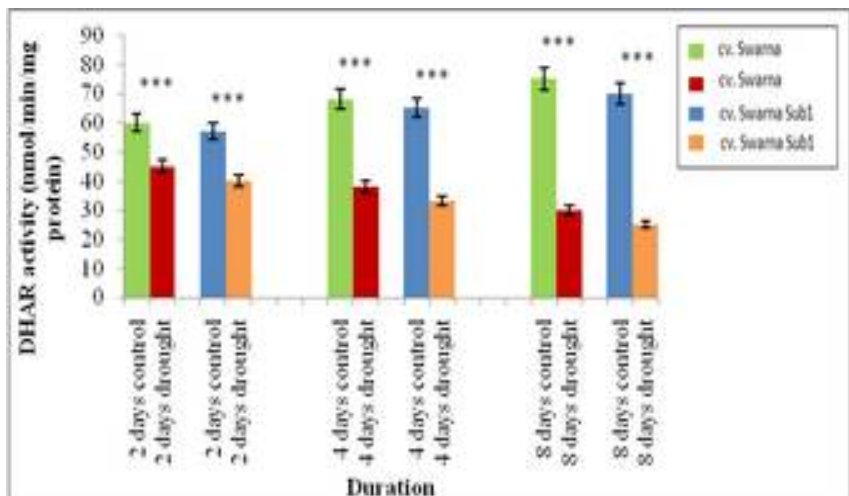

Fig. 4. Changes of dehydroascorbate (DHAR) activity through days of dehydration of cv. Swarna and Swarna Sub1. Data are presented in bars with $\pm S E \quad(n=3)$ from independent experimental sets and the significant values were represented as ${ }^{*}(p \leq 0.05),{ }^{* *}(p \leq 0.01)$ and ${ }^{* * *}(p \leq 0.001)$ by student's t-test to denote the significant differences between control and treatment through duration of dehydration. cv. Swarna than Swarna Sub1 when compared to control. The similar trend was also maintained considering those varieties respectively, however, became maximum 1.78 fold at 8 days.

Recycling of ascorbate into its reduced form we have monitored the activity of DHAR for cv. Swarna and Swarna Sub1 through varying duration of drought (Fig. 4). Regardless of varieties activity of DHAR was subdued when the plants exposed to dehydration stress in a proportionate manner. Thus, the maximum in activities at 8 days of drought resulted depletion by 66.66 and $64.28 \%$ for cv. Swarna and Swarna Sub1 respectively in the present experiment. Still, the reduction in activities were significant $(p \leq 0.001)$ all through the duration irrespective of varieties. This suggests the plants ability to recruit more reduced ascorbate in activities to cellular dehydration to cope up its effect. Undoubtedly, cv. Swarna was more sensitive to change the DHAR activity at every stages of dehydration.

Finally the responses of sub1A QTL to dehydration, that otherwise an induction of oxidative stress was documented by biomolecules peroxidation. Protein oxidation through development of carbonyl content was the most variable all through the days of dehydration (Fig. 5). Still, the maximum variation was observed at 4 days of dehydration where cv. Swarna and Swarna Sub1 were varied by decrease (70\%) and increase (1.8 fold) as compared to control respectively. On contrary, at 8 days not significant variation was observed in both varieties under control and dehydration condition. Therefore, the inconsistent 


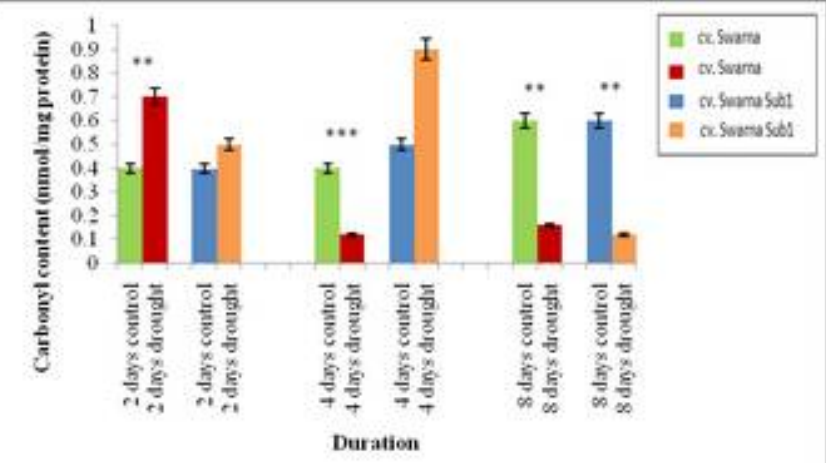

Fig. 5. Changes of carbonyl content (protein oxidation) through days of dehydration of cv. Swarna and Swarna Sub1. Data are presented in bars with $\pm S E \quad(n=3)$ from independent experimental sets and the significant values were represented as ${ }^{*}(p \leq 0.05),{ }^{* *}(p \leq 0.01)$ and ${ }^{* * *}(p \leq 0.001)$ by student's t-test to denote the significant differences between control and treatment through duration of dehydration.
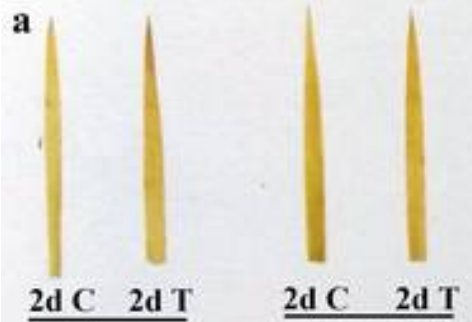

cv. Swarna
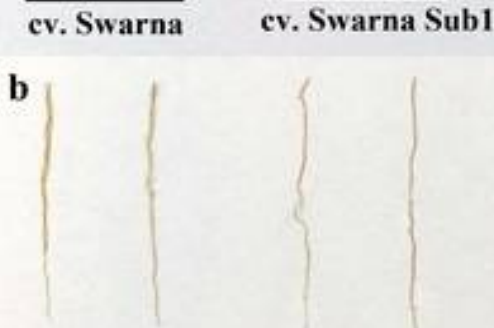

2d C 2d T

cv. Swarna

$2 \mathrm{dC} \quad 2 \mathrm{~d}$

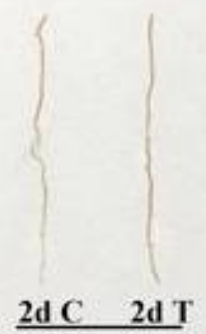

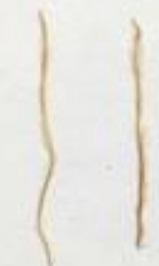

$4 d \mathrm{C} \quad 4 \mathrm{dT}$ nature of protein oxidation has appeared to be dehydration days dependent and also variable with regards to sub1A and non sub1A QTL.

The accumulation of $\mathrm{H}_{2} \mathrm{O}_{2}$ and thereby its complex with $\mathrm{DAB}$ presented a significant variation of $\mathrm{H}_{2} \mathrm{O}_{2}$ sensitivity in rice, however, irrespective of cultivars (Fig. 6a). It is quite interesting to note that initial period of dehydration had scored hardly any significant variation between control and treatment. Still, the gradually distributed patches of peroxide-DAB complex not consistently but diffused in leaf base and apical portion. This trend is more vividly expressed when cv. Swarna and Swarna Sub1 experienced maximum days of duration for dehydration. Not necessarily to mention that cv. Swarna at higher days were more sensitive to $\mathrm{H}_{2} \mathrm{O}_{2}$. Contextually, the trend of sensitivity was
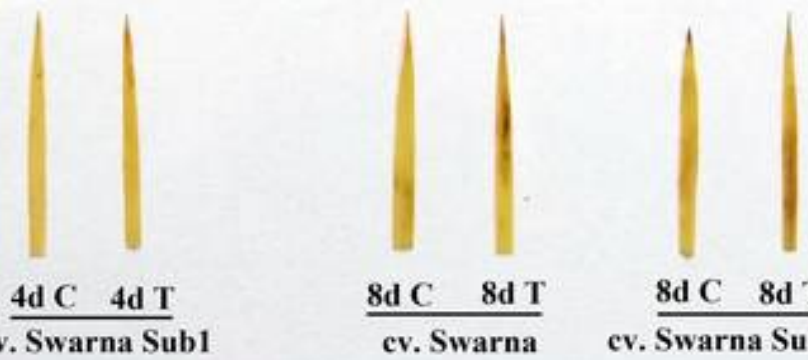

cv. Swarna

$8 d \mathrm{C} \quad 8 \mathrm{~d} T$ cv. Swarna cv. Swarna Sub1

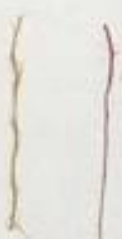

$8 d \mathrm{~d} \quad 8 \mathrm{~d} T$

Fig. 6. Histochemical detection of peroxidase by 3'3'-diaminobenzidine (DAB) staining in leaves (a) and roots (b) of cv. Swarna and Swarna Sub1 respectively. 'C' represents control, ' $T$ ' represents treatment (drought) and 'd' represent the consecutive days of experiment through test. Various treatments as $2 \mathrm{~d}$ C, $2 \mathrm{~d}$ T, $4 \mathrm{~d} \mathrm{C}, 4 \mathrm{~d}$ T, $8 \mathrm{~d}$ C and $8 \mathrm{~d}$ T represents 2 days control, 2 days drought, 4 days control, 4 days drought, 8 days control and 8 days drought respectively.

a

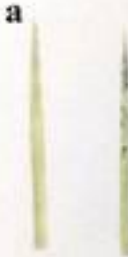

$2 \mathrm{~d}$ C $2 \mathrm{~d}$ T cv. Swarna b

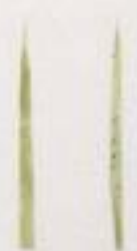

$2 d \mathrm{~d} \quad 2 \mathrm{dT}$

cv. Swarna Sub1

\section{$4 d \mathrm{C} \quad 4 d \mathrm{~T}$}

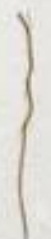

$8 \mathrm{~d} \mathrm{C} \quad 8 \mathrm{dT}$

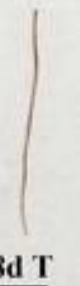

.


similarly consistent with the roots where dehydration duration would be the key factor to accumulate more peroxide-DAB product (Fig. $6 \mathrm{~b})$.On the contrary, duration of 4 days appear to be more prone to $\mathrm{H}_{2} \mathrm{O}_{2}$ accumulation. cv. Swarna unlike leaf sheath accumulated more ROS than cv. Swarna. Likewise another, the initial ROS, the superoxide $\left(\mathrm{O}_{2 .}{ }^{-}\right)$were more convincing to distinguish in sensitivity of two cultivars in the present experiment. This is clearly demonstrated that both the rice cultivars were more variable to the degrees of duration by 8 days maximally to accumulate $\mathrm{O}_{2}$. In leaf sheath $\mathrm{cv}$. Swarna Sub1 was more diffused in NBT mediated superoxide through the leaf sheath, however, more progressed towards tips (Fig. 7a). This was also preceded from the earlier days of dehydration but with inconspicuous manner. The trend was also transmitted to root also (Fig. 7b). Here, density gradient of superoxide accumulation followed a linear trend of increase through the dehydration. cv.Swarna with significantly varied to accumulate more superoxide in the root hairs that progressed from root tip to the basal portion.

\section{Discussion}

In context to the responses of dehydration tolerance of sub1A QTL possessing rice genotypes, the selective physiological indices were more significant to denote the possible tolerance of plants. Dehydration tolerance has been documented in almost the crops where sustainability and productivity is most important. Still, in the present experiment a submergence tolerant genetic constituent has been deciphered by interference of dehydration stress. sub1A QTL in rice is undoubtedly for quiescence strategy adoption (15). Therefore, its behaviour to shortage of water may be relevant to represent the rice genotypes for both submergence and dehydration tolerance. Any physiological process is the manifestation of perception of environmental stimuli inducing the expression of gene(s) either up or down regulation (16). Likewise, dehydration stress by withdrawn of irrigation may often link to loss of turgidity of cell membrane (17). This causes an uneven distribution of energy, particularly, under high intensities of light leading to a perturbed of redox of membrane. With generation of ROS and its consecutive peroxidation of lipid and protein residues of the membrane are the results and membrane permeability is disrupted (18). Thus, in the present experiment a significant loss of electrolyte leakage more in cv. Swarna Sub1 was observed. The permeability of membrane in cv. Swarna Sub1 may be linked to dehydration stress to balance the solute concentrations in dehydrated cytosol. As a consequence of loss of electrolytes from any plant species the other physiological modules would be carry forward the effects of dehydration stress. To compensate the deviation of carbon metabolism and restore the photosynthetic $\mathrm{CO}_{2}$ enrichment, few other anaplerotic reactions are important (19). NADPmalic enzyme, such of those which enriches the $\mathrm{CO}_{2}$ from malate in TCA cycle energy yielding metabolism (20). Thus, to reduce organic acid load in the photosynthetic tissues and more to extract $\mathrm{CO}_{2}$ to engage in reducing sugars, few plant species are ahead of stress tolerant to others. In general, $\mathrm{C}_{4}$ plants with existence of NADP malate metabolism; however, specifically for $\mathrm{C}_{4}$ photosynthetic reactions are important for normal course of $\mathrm{CO}_{2}$ concentration mechanism (21). Still, non photosynthetic NADP(ME) has frequently been contexted for stress tolerant indices even in these rice $\left(\mathrm{C}_{3}\right)$ species. With this background evaluation of NADP(ME) in both cv. Swarna and Swarna Sub1, the $\mathrm{C}_{3}$ species revealed interesting information. This was more convinced with the nature of responses to light and darkness, an essential edaphic factors for regulation of NADP(ME) at molecular level. Regardless of cultivars the responses of enzyme activity becomes proportional to the function of substrate concentrations. This was more commonly with the influences of environmental factors as considered light and darkness herein the present experiment. NADP(ME) is switched on its active form by dithiol reduction of amino acid residues on active site (22). In case of $C_{4}$ plants the induction of activity is more complex with other chemical or cellular elicitors. However, for cv. Swarna Sub1 the mechanism of activity though dependent on light/darkness, the extent of regulation is more lenient than cv. Swarna. This could be anticipated with the more sustainability of redox towards reduced state as adhered to sub1A QTL. In fact, sub1A QTL exercising the post submergence anoxic condition could withstand the oxidative stress by sustaining more reduced redox. In compare to non sub1A QTL possessing rice genotypes, this reduced redox might be supportive for maintenance of other light inductive enzyme to its active form. NADP(ME) could be illustrated one of those enzymes despite of $\mathrm{C}_{3}-\mathrm{C}_{4}$ discretion in plant species as rice in the present case. Therefore, even for dehydration responses coupled to oxidative exposure, NADP(ME) activity and its modulation would be a biomarker in $\mathrm{C}_{3}$ plants (e.g. rice) also. NADP(ME) has already been implicated as a redox indicator in the plants. This is more prevalent when it considers the pull of NADP $(\mathrm{H})+$ $\mathrm{H}^{+}$accumulated depriving $\mathrm{CO}_{2}$ reduction. The later is much contextual in any facets of environmental stress that closes the stomata letting the $\mathrm{CO}_{2}$ limited for reduction by $\mathrm{NADP}(\mathrm{H})+\mathrm{H}^{+}$. So, a precise ratio of $\mathrm{NADP}(\mathrm{H})+\mathrm{H}^{+} / \mathrm{NADP}^{+}$would compensate the depleted status of photosynthetic tissues. The retrieval of glutathione, ascorbic acid, the non enzymatic antioxidant with cyclic redox system of $\mathrm{NADP}(\mathrm{H})+\mathrm{H}^{+} / \mathrm{NADP}^{+}$would be an indicator for stress tolerance. In lineage to maintenance of redox through enzyme mediated pathway the two rice cultivars herein recorded 
their differential antioxidation process. Admitting the oxygen recovery under de-submergence following exposure of an oxidative tension, cv. Swarna Sub1 also displays its superiority. sub1A QTL is more admissible to ethylene regulated gibberellic acid metabolism which favours the shortening of internodes and leaf sheath. In addition, this also favours the anaerobic mode of respiration making a pathway of reducing equivalent like NADPH.

The other redox carrying biomolecules, particularly, sulphur enriched one like glutathione is most important (23). Thus, the trend in GSH and GSSG that was expected to be variable but remained more stable regardless the rice genotypes. As compared to control for both $\mathrm{cv}$. Swarna and Swarna Sub1, the retention of reduced GSH but not with oxidised form might bear some relevance. This might be related with involvement of reduced glutathione to quench the generated ROS and thereby the depletion results. The cyclic transformation of reduced (GSH) and oxidised (GSSG) is more frequent in other references with changing the cellular redox under abiotic stress. The pattern of consumption of GSH and its retrieval with regard to oxidative stress tolerance is precisely established by GSH and GSSG ratio (24). This is also tuned herein the present experiment where cv. Swarna Sub1 is significantly marked with more GSH content by readily retrieval from GSSG all through the dehydration period. Thereby, cv. Swarna Sub1 would be more tolerant even in water deficit or dehydration induced oxidative stress. Ascorbate metabolism though established in stress tolerance with also in two forms: oxidised (ascorbate) and reduced (dehydrate ascorbate) (25). Thus, the metabolic conversion for dehydroascorbate to ascorbate by the dehydroascorbate reductase activity has been an index for oxidative stress tolerant. cv. Swarna and Swarna Sub1 had almost the similar trend to activities all through the dehydration period. This otherwise indicate any underlying mechanism more dependent than ascorbate metabolism would be supportive in this case. So, cellular redox and its sustenance by other biomolecules would be probed for sub1A QTL when facing dehydration stress. Undoubtedly, plants are to suffer from shifting of anaerobic to aerobic stress on desubmergence (26). De-submergence here technically refers the transition from complete submergence (vis-à-vis anaerobic condition) to non submergence (vis-à-vis normal aerobic condition). Contextually, under condition of complete submergence plants occasionally face with a sort of osmotic deficit in the tissue particularly, for roots. It is due to inadequate root hydraulic conductivity under anoxic condition of submergence that impedes energy dependent water uptake.

Factually, plants are more affected with post submergence oxidative stress than submergence anoxia does. So, a shifting of redox also reflected with ROS generated protein oxidation on membrane. Under de-submergence plants experience more earlier loss of integral membrane proteins than lipid residues. It is more specific responses of dehydration impulses through prolong duration, however, for both the cultivar herein to experience the tissue moisture deficit in a non interrupted manner. In a non interrupted manner of tissue dehydration, the genetic plasticity of plant species could stabilize the detrimental effects. This is also with no encryption regardless of $s u b 1 A$ and non sub1A genotypes. For both the cases the regulation of carbonyl content, particularly, at latter period of dehydration could be imparted as induced adaptability. Therefore, protein oxidation might not be the criterion for distinguishing sub1A QTL with non sub1A QTL. The differential activity of $\mathrm{O}_{2}$. is very much tissue specific, however, also proved in the present experiment. Thus, cv. Swarna and Swarna Sub1 with respect to their sub1A QTL responded well still, with significant variation for $\mathrm{O}_{2}$.- accumulation. Submergence with inundation often linked to an in-built anoxic or hypoxic that results not much with scope to ensure oxidative damages. De-submergence were withdrawn of excess water is the key and a sudden exposure to high oxidative tension causes a significant ROS generation. In the present experiment, dehydration often linked to full or partial oxidative exposition is also sensitized by sub1A QTL. Thus, in the present experiment it may prove the compatibility of dehydration perception with oxygen induced ROS generation. Similarly, the accumulation of $\mathrm{H}_{2} \mathrm{O}_{2}$ but with varied quantities is also evident for DAB staining. $\mathrm{H}_{2} \mathrm{O}_{2}$ accumulation in tissue is accomplished with dual roles: an ROS intermediate to degenerate the biomolecules and/ or a molecular elicitation for different cellular process (27). The later is very often aligned within the threshold concentration of $\mathrm{H}_{2} \mathrm{O}_{2}$ within cellular environment. Thus, cv. Swarna and Swarna Sub1 have not been demarked well under dehydration stress with regards to $\mathrm{H}_{2} \mathrm{O}_{2}$ accumulation. $\mathrm{O}_{2}{ }^{-}$is the initiation to establish oxidative stress in plants through series of downstream reactions. sub1A QTL has also been analysed of its sensitivity to induced ROS (28). Dehydration refers the storage of water in cytosol and cellular organelle that regulate closing of stomata. This limits the entry of $\mathrm{CO}_{2}$ and excess reducing equivalent would be forced to reduce molecular oxygen $\left(\mathrm{O}_{2}\right)$ by its electron into $\mathrm{O}_{2}$. In rice almost the abiotic stressors are secondarily effective ROS generation which is not any exception in the present experiment where both the varieties are marked with distribution of $\mathrm{O}_{2 .}{ }^{-}$as distinct intensities through formazan in leaves than roots. It assumes that on dehydration the leaves may regulate the water loss by stomatal regulation and thereby, NADPH could spill the electrons from electron transport chain and 
reduce the $\mathrm{O}_{2 .}{ }^{-}$(29). Dehydration escape strategy in rice is facilitated by rolling of lamina in tolerant rice cultivars (30). This ensures more ROS generation that otherwise may be of constraints to plants.

\section{Conclusion}

In conclusion, the rice genotypes with possessing of sub1A QTL is likely more accommodating to the dehydration stress. This is not through manifestation of any particular physiological consideration but with a collection of contributing factors. cv. Swarna Sub1 is more reliable to cope up the dehydration stress either to consider at post submergence or to cultivate under soil moisture deficit condition. The most significant path that follows the better sustenance of dehydration responses produced to be oxidative redox maintenance which is lacked in cv. Swarna. Therefore, besides the vegetative and other physiological selective pressures for quiescence strategies redox homeostasis comes most important. This is more lenient with glutathione metabolism and its recovery under depleted redox of dehydration. Even rice being a $\mathrm{C}_{3}$ species the exercise of anaplerotic reactions for $\mathrm{CO}_{2}$ enrichment by NADP-ME activities would also be contributing in proportion to the loss of carbohydrate under dehydration.

\section{Competing Interest}

The authors declare that they have no competing interests.

\section{Acknowledgements}

The experimental work is financially supported by DST-INSPIRE fellowship, Govt. of India, New Delhi.

\section{Authors' Contribution}

IS carried out the entire experiment and statistical analysis of collected data. BS, AG and AKD assisted in the experiment. MKA hypothesized the paper concept and written up the manuscript.

\section{References}

1. Ismail AM, Ella ES, Vergara GV, Mackill DJ. Mechanisms associated with tolerance to flooding during germination and early seedling growth in rice (Oryza sativa). Annals of Botany. 2008; 103(2):197-209. https://doi.org/10.1093/aob/mcn211

2. Colmer TD, Armstrong W, Greenway H, Ismail AM, Kirk GJ, Atwell BJ. Physiological mechanisms of flooding tolerance in rice: transient complete submergence and prolonged standing water. In: Progress in Botany 2014 (pp. 255-307). Springer, Berlin, Heidelberg. https://doi.org/10.1007/978-3-642-38797-5 9

3. Jackson MB, Ram PC. Physiological and molecular basis of susceptibility and tolerance of rice plants to complete submergence. Annals of Botany. 2003; 91(2):227-41. https://doi.org/10.1093/aob/mcf242

4. Singh US, Dar MH, SINGH S, Zaidi NW, Bari MA, Mackill DJ, Collard BC, Singh VN, Singh JP, Reddy JN, Singh RK. Field performance, dissemination, impact and tracking of submergence tolerant (Sub1) rice varieties in South Asia. SABRAO Journal of Breeding \& Genetics. 2013; 45(1): 112-31.

5. Vijayan J, Senapati S, Ray S, Chakraborty K, Molla KA, Basak N, Pradhan B, Yeasmin L, Chattopadhyay K, Sarkar RK. Transcriptomic and physiological studies identify cues for germination stage oxygen deficiency tolerance in rice. Environmental and Experimental Botany. 2018; 147:234-48 https://doi.org/10.1016/j.envexpbot.2017.12.013

6. Sarkar RK, Bhattacharjee B. Rice genotypes with SUB1 QTL differ in submergence tolerance, elongation ability during submergence and re-generation growth at re$\begin{array}{lll}\text { emergence. } & \text { Rice. } & \text { 2011; }\end{array}$ https://doi.org/10.1007/s12284-011-9065-Z

7. Alpuerto JB, Hussain RM, Fukao T. The key regulator of submergence tolerance, SUB1A, promotes photosynthetic and metabolic recovery from submergence damage in rice leaves. Plant, Cell \& Environment. 2016;39(3):672-84. https://doi.org/10.1111/ pce.12661

8. Jambunathan N. Determination and detection of reactive oxygen species (ROS), lipid peroxidation, and electrolyte leakage in plants. In: Plant Stress Tolerance 2010 (pp. 291-97). Humana Press. https://doi.org/10.1007/978-1-60761-702-0 18

9. Iglesias AA, Andreo CS. Purification of NADP-malic enzyme and phosphoenolpyruvate carboxylase from sugar cane leaves. Plant and Cell Physiology. 1989;30(3):399-405.

10. Kocsy G, Galiba G, Brunold C. Role of glutathione in adaptation and signalling during chilling and cold acclimation in plants. Physiologia Plantarum. 2001;113(2):158-64.

https://doi.org/10.1034/j.1399-3054.2001.1130202.x

11. Nakano Y, Asada K. Hydrogen peroxide is scavenged by ascorbate-specific peroxidase in spinach chloroplasts. Plant and Cell Physiology. 1981;22(5):867-80.

12. Verbeke P, Clark BF, Rattan SI. Modulating cellular aging in vitro: hormetic effects of repeated mild heat stress on protein oxidation and glycation. Experimental Gerontology. 2000;35(6-7):787-94. https://doi.org/10.1016/S0531-5565(00)00143-1

13. Li J, Pandeya D, Nath K, Zulfugarov IS, Yoo SC, Zhang H, Yoo JH, Cho SH, Koh HJ, Kim DS, Seo HS. ZEBRANECROSIS, a thylakoid-bound protein, is critical for the photoprotection of developing chloroplasts during early leaf development. The Plant Journal.2010;62(4):713-25. https://doi.org/10.1111/j.1365-313X.2010.04183.x

14. Flohe L. [10] Superoxide dismutase assays. In: Methods in enzymology 1984 (Vol. 105, pp. 93-104). Academic Press. https://doi.org/10.1016/S0076-6879(84)05013-8

15. Zeng N, Yang Z, Zhang Z, Hu L, Chen L. Comparative Transcriptome combined with proteome analyses revealed key factors involved in Alfalfa (Medicago sativa) response to waterlogging stress. International journal of Molecular Sciences. 2019;20(6):1359. https://doi.org/10.3390/ijms20061359

16. Saha I, Sarkar B, Ghosh A, De AK, Adak MK. Abscisic acid induced cellular responses of sub1A QTL to aluminium toxicity in rice (Oryza sativa L.). 
Ecotoxicology and Environmental Safety.2019;183: 109600. https://doi.org/10.1016/j.ecoenv.2019.109600

17. Saha I, De AK, Sarkar B, Ghosh A, Dey N, Adak MK. Cellular response of oxidative stress when sub1A QTL of rice receives water deficit stress. Plant Science Today. 2018; 5(3):84-94. https://doi.org/10.14719/pst.2018.5.3.387

18. Rizwan M, Mostofa MG, Ahmad MZ, Imtiaz M, Mehmood S, Adeel M, Dai Z, Li Z, Aziz O, Zhang Y, Tu S. Nitric oxide induces rice tolerance to excessive nickel by regulating nickel uptake, reactive oxygen species detoxification and defense-related gene expression. Chemosphere. 2018;191:23-35. https://doi.org/10.1016/j.chemosphere.2017.09.068

19. Spencer W, Bowes G. Photosynthesis and growth of water hyacinth under $\mathrm{CO}_{2}$ enrichment. Plant Physiology. https://doi.org/10.1104/pp.82.2.528

20. Omena-Garcia RP, Araújo WL, Gibon Y, Fernie AR, Nunes-Nesi A. Measurement of Tricarboxylic Acid Cycle Enzyme activities in plants. In: Plant Respiration and Internal Oxygen 2017; pp. 167-82. Humana Press, New York, NY. https://doi.org/10.1007/978-1-4939-7292-0 14

21. Rao X, Dixon RA. The differences between NAD-ME and NADP-ME subtypes of C4 photosynthesis: more than decarboxylating enzymes. Frontiers in Plant Science. 2016;7:1525. https://doi.org/10.3389/fpls.2016.01525

22. Murmu J, Chinthapalli B, Raghavendra AS. Light activation of NADP malic enzyme in leaves of maize: marginal increase in activity, but marked change in regulatory properties of enzyme. Journal of Plant Physiology. https://doi.org/10.1078/0176-1617-00844

23. de Carvalho Oliveira RA, de Andrade AS, Imparato DO, de Lima JG, de Almeida RV, Lima JP, de Bittencourt Pasquali MA, Dalmolin RJ. Analysis of Arabidopsis thaliana Redox Gene network indicates evolutionary expansion of class iii peroxidase in plants. Scientific Reports. 2019;9(1):1-9. https://doi.org/10.1038/s41598019-52299-y
24. Mostofa MG, Hossain MA, Fujita M. Trehalose pretreatment induces salt tolerance in rice (Oryza sativa L.) seedlings: oxidative damage and co-induction of antioxidant defense and glyoxalase systems. Protoplasma. https://doi.org/10.1007/s00709-014-0691-3

25. Han B, Duan X, Wang Y, Zhu K, Zhang J, Wang R, Hu H, Qi F, Pan J, Yan Y, Shen W. Methane protects against polyethylene glycol-induced osmotic stress in maize by improving sugar and ascorbic acid metabolism. Scientific Reports. 2017;7:46185. https://doi.org/10.1038 $\underline{\text { srep46185 }}$

26. Luo FL, Nagel KA, Scharr H, Zeng B, Schurr U, Matsubara S. Recovery dynamics of growth, photosynthesis and carbohydrate accumulation after de-submergence: a comparison between two wetland plants showing escape and quiescence strategies. Annals of Botany. 2010;107(1):49-63. https://doi.org/10.1093/aob/mcq212

27. Liu Q, Zheng L, He F, Zhao FJ, Shen Z, Zheng L. Transcriptional and physiological analyses identify a regulatory role for hydrogen peroxide in the lignin biosynthesis of copper-stressed rice roots. Plant and Soil. 2015;387(1-2):323-36. https://doi.org/10.1007/s11104-014-2290-7

28. Saha I, De AK, Ghosh A, Sarkar B, Dey N, Adak MK. Preliminary Variations in Physiological Modules When sub1A QTL Is under Soil-Moisture Deficit Stress. American Journal of Plant Sciences. 2018; 9(04):732. https://doi.org/10.4236/ajps.2018.94058

29. Takahashi F, Suzuki T, Osakabe Y, Betsuyaku S, Kondo Y, Dohmae N, Fukuda H, Yamaguchi-Shinozaki K, Shinozaki K. A small peptide modulates stomatal control via abscisic acid in long-distance signalling. Nature. https://doi.org/10.1038/s41586-018-0009-2

30. Zhang J, Zhang H, Srivastava AK, Pan Y, Bai J, Fang J, Shi H, Zhu JK. Knockdown of rice microRNA166 confers drought resistance by causing leaf rolling and altering stem xylem development. Plant physiology. 2018; 176(3):2082-94. https://doi.org/10.1104/pp.17.01432 